\title{
Impact of Social Network Usage on Academic Performance of the Vietnamese Students
}

\author{
Le Thanh Tung ${ }^{1, *}$, Tang $\mathrm{My} \mathrm{Ha}^{2}$ \\ ${ }^{\mathbf{1}}$ Faculty of Economics and Public Management, Ho Chi Minh City Open University, Vietnam \\ ${ }^{2}$ Faculty of Economics, Ho Chi Minh City University of Economics and Finance, Vietnam \\ *Corresponding Author: tung.lt@ou.edu.vn
}

Received April 9, 2020; Revised July 14, 2020; Accepted August 5, 2020

\begin{abstract}
Cite This Paper in the following Citation Styles
(a): [1] Le Thanh Tung, Tang My Ha, "Impact of Social Network Usage on Academic Performance of the Vietnamese Students," Universal Journal of Educational Research, Vol. 8, No. 9, pp. 4179-4186, 2020. DOI: 10.13189/ujer.2020.080944.
\end{abstract}

(b): Le Thanh Tung, Tang My Ha (2020). Impact of Social Network Usage on Academic Performance of the Vietnamese Students. Universal Journal of Educational Research, 8(9), 4179-4186. DOI: 10.13189/ujer.2020.080944.

Copyright $(2020$ by authors, all rights reserved. Authors agree that this article remains permanently open access under the terms of the Creative Commons Attribution License 4.0 International License

\begin{abstract}
Social networks and communication on the Internet have an important role in people's daily life worldwide. This paper examines the impact of Social network usage on the Academic performance of students. The research data were collected from a stratified sampling survey including 576 Vietnamese undergraduate students. The research model has five independent variables (Perceived usefulness, Perceived ease of use, Social influences, Facilitating conditions, Community identity), one mediating variable (Social network usage), and one dependent variable (Academic performance). The study methods include the Cronbach's alpha test, the Exploratory factor analysis, the Confirmatory factor analysis, and the Structural equation modeling are employed to quantitatively analyze the relationship among variables. The result finds that there are positive and significant impacts of Perceived usefulness, Perceived ease of use, Social influences, Community identity on Social network usage. The impact of Facilitating conditions on Social network usage is positive, however, it is not significant. The result also concludes that there is a positive and significant impact of Social network usage on the Academic performance of students. Besides, the empirical statistical data indicates that social networks are really a popular and familiar tool for helping students to communicate with each other in Vietnam. Finally, the study result suggests that educational managers may use social networks as an informal tool to enhance not only the academic performance of students but also other educational activities in universities.
\end{abstract}

Keywords Academic Performance, Educational Manager, Social Network Usage, Student

\section{Introduction}

In the context of the blooming of information technology, communications on the Internet play an important role in almost every work of human daily life. The statistics have presented a robust growth in using the Internet and digital technology for recent years. The social network can be defined as internet-based applications that allow the creation and exchange of content generated by users (Kaplan \& Haenlein, 2010). Through social networks on the internet, people can fastly communicate with each other by a variety of platforms (Dholakia et al., 2004; Corrocher, N., 2011; Nadkarni \& Hofmann, 2012; Martin et al., 2016; Shepherd \& Lane, 2019; Abed, 2020). Social networks are no longer merely playing the role of connecting relatives and friends but also developing as one of the most useful business activities, system operation, advertising campaigns, and communication channels (Martin et al., 2016; Torres et al., 2020; Abed, 2020). Social networks are increasingly penetrating and having a stronger impact on the academic environment worldwide (Rains \& Young, 2009; Kirschner \& Karpinski, 2010; Sánchez et al., 2014; Ainin et al., 2015; Amin et al., 2016; Al-Rahmi et al., 2017; Bond et al., 2017). 
There are many students who usually daily access the internet and spend their time on social networks. Students are young people, favor to experience, and prefer to explore new trends. Some reasons can explain why students always spend much time using social networks. Social networks can freely provide whatever users want such as upload images, talk, make new friends as well as comment on the lives of other people (Karadkar, 2015). Obviously, social media networks can help the students to express their opinions, establish and maintain relationships, seek information, and interact with other users (Rains \& Young, 2009; Ainin et al., 2015; Al-Rahmi, 2017). Besides, the social network allows users to easily create, communicate, edit, or update their contents. With the internet, the virtual world of social networks can be known as a robust way to free share of thoughts.

Based on many strong points, obviously, social media is an effective tool for the learning activities of students. The social network has been indicated to have an impact on the learning activities of students. There are some positive aspects of social networks in an academic environment, for example, helping to seek information, well connecting with the community, fastly finding references. On the other hand, the social network also has some certain negative aspects, for example, wasting a lot of time using social media, make hallucinatory, or entangled in illegal activities. In order to quantitatively analyze the impact of social network usage on the academic performance of students, we will have a survey focusing on using the social network in the academic environments in Vietnam, a country in Southeast Asia, which has a dynamic education market now. The paper has five sections. Section 2 presents the literature review. The methodology and data are shown in Section 3. The results and discussions will be done in Section 4. Finally, Section 5 provides conclusions and implications for educational managers.

\section{Literature Review}

The social network is becoming a popular communitive tool because it helps fast shares, expands the news, ideas, career interests, market information, and other forms of expression by virtual communities and networks on the internet. The student is the highest spending time in using the social network; therefore, there are some previous studies which investigate the impact of social network usage on the learning activities of the student in some countries. However, some different kinds of results were found in the previous studies.

In a study in Turkey, Sanchez et al. (2014) studied the impact of using the Facebook network on the academic activities of students with a sample of 214 respondents. The authors used the structural equation model to identify the factors that might motivate the students to adopt and use social network tools (eg., Facebook) for educational targets.
Their result indicated that social influence and social relations were the most important factor in predicting the adoption of Facebook. In detail, students were influenced by social networks to establish or maintaining contact with other people with whom they shared interests or collected the information from others. Their result concluded that the impact of social network usage on students' learning depended on the purpose of using social networks.

In another study in Turkey, Köse (2015) surveyed 102 university students (from many faculties and disciplines) in this country. The author noted that social media had a great impact on people's daily life and the education field was one of these fields in which social media had remarkable popularity. The study result showed that social network affects students in a positive direction. However, social networks could also negatively affected student's ability to raise their awareness and adversely affected their social and physical aspects.

With another research, Michikyan et al. (2015) studied the impact of Facebook on student activities at some United States colleges. There were 261 respondents whose age ranged from 18 to 30 (the average age is 20 years old). The result showed that social networks had a positive impact on student activities through the spread of student support services that schools were implementing. The thematic analysis found that there was over $14 \%$ of the Facebook status updates related to academic themes. Furthermore, the positive states were more frequent than the negative sign. However, students expressing negative states were who had lower academic points.

Besides, Ainin et al. (2015) also researched the impact of social network usage on student learning activities. The survey sample collected from 1165 students at universities in Malaysia. The result confirmed that using social networks had a positive impact on the learning activities of students. In which, social media usage helped students better access to learning activities, especially teamwork target. However, in the case of Saudi Arabia, Shahzad et al. (2015) used a sample of 108 students to explore the impact of social network usage on learning activities. The result concluded that there was the non-significance impact of social media usage on the weekly learning outcomes of students in the study sample.

From another aspect, Tandoc et al. (2015) did an empirical study regarding the relationship between Facebook use, envy, and depression among college students. The authors used a database collected from a survey of 736 college students. The results found that using social networks could cause depression for users. Therefore the results implied a negative impact of using Facebook on student learning outcomes. Besides, the authors noted that when the envy of users is controlled it could help actually lessens depression.

Besides, Amin et al. (2016) conducted a survey of 300 students in Canada to explore the impact of social networks on student learning. The targeted objects of the survey are 
to find out the impact of two social networks, Facebook and Twitter, on learning. The research model only explained $29.9 \%$ of the variation in student learning outcomes. It was reasonable because there were many factors affecting the learning outcomes of this research object. Regression results showed that social networks positively affected learning outcomes, in which Facebook had a stronger effect comparison other social networks.

Following previous results, although there are some recent studies conducted that focus on the topic analysing the impact of social network usage on learning outcomes of students in both developed countries (such as United States, Canada) and developing countries (such as Pakistan, Malaysia). However, the research results are inconsistent, in which some studies show a positive effect (for example, Michikyan et al., 2015; Khalid, 2017) but there is also evidence implying negative extremes (eg., Köse, 2015) or cannot conclude about the real relationship between two variables (for example, Shahzad et al., 2015). So it is can be assumed, the direction of the impact may depend on the country's educational characteristics, the academic characteristics, and the habit of using the social skills of students in a specific country.

\section{Methodology}

\subsection{Research Model and Hypothesis}

Academic performance is depended on many factors that are not only coming from the individual students but also the social environment. There are some variables that help to identify the factors influencing the academic performance of students. Our research model has only a direction reflecting coming from the users of the social network in the academic environment so we ignore other factors in order to have the most suitable model for quantitative analysis. The research model has one dependence variable (Academic Performance) and 5 independence variables including the Perceived Usefulness, Perceived Ease of Use, Social Influence, Facilitating Conditions, Community Identity. Besides, there is a mediating variable titled Social Network Usage.

The Perceived Usefulness variable is defined as the degree to which an individual believes that his or her social networks using will enhance his/her ability to communicate, collaborate and exchange information (Davis, 1989; Sanchez et al., 2014). The Perceived Ease of Use variable can be understood as the degree to which an individual believes that using social networks will not require physical and mental efforts (Davis, 1989; Sanchez et al., 2014). The definition of Social Influence is the degree to which an individual perceives the approval of others for the use of social networks is important to them (Venkatesh et al., 2003; Sanchez et al, 2014). The Facilitating Conditions variable can be referred to as the extent to which an individual believes that there are technical support and appropriate guidance in using social networks (Venkatesh et al., 2003; Sanchez et al., 2014). The Community Identification variable can be described as a personal identity with a virtual community amongst users who share the same interests (Mazman \& Usluel, 2010; Kim et al., 2012). The scale of Social Network Usage is defined as a scale in which social network users desire to create new relationships and maintain old relationships (Kalpidou et al., 2011) or create a social presence (Cheung et al., 2011). Finally, the Academic Performance variable is considered an entertainment activity that interferes with the academic performance of students (Rouis et al., 2011). The study model is represented in the following form (see Figure 1).

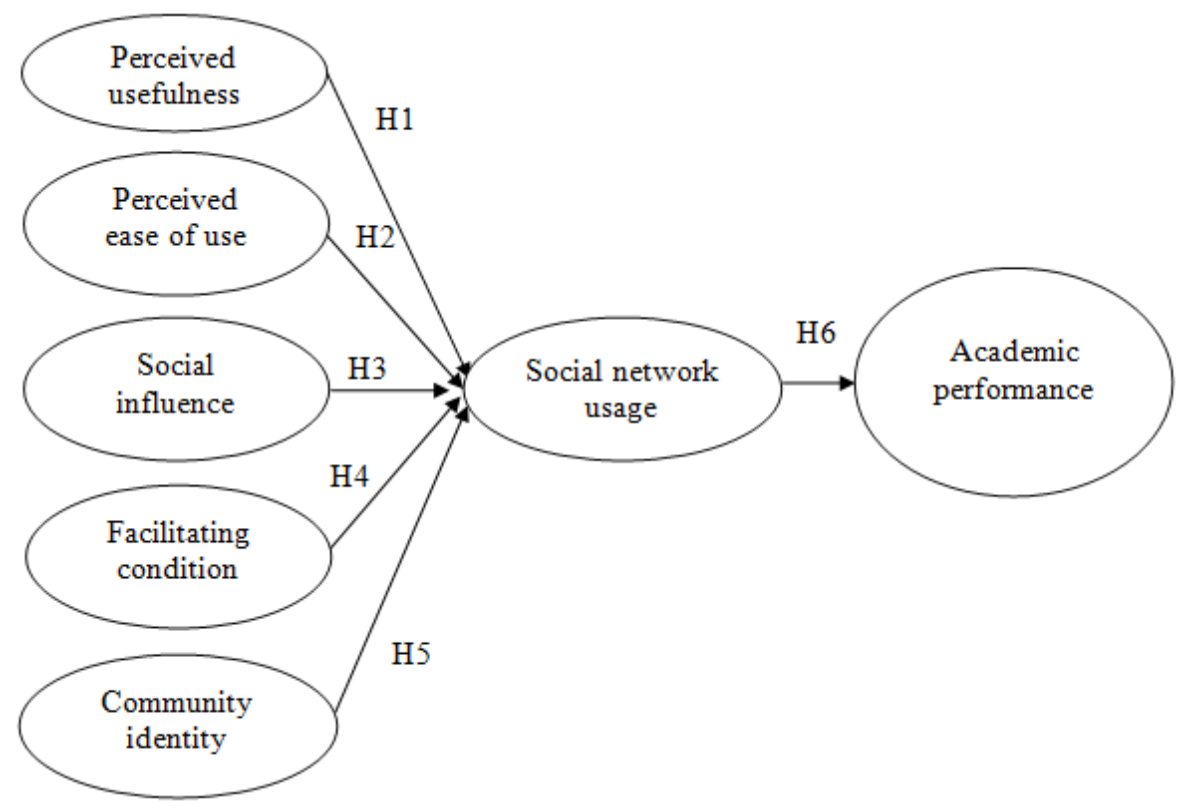

Figure 1. The research model 
Based on the previous studies (Sanchez et al., 2014; Ainin et al., 2015), to explore the relationships between the independent variables and the mediating variable, there are five hypotheses used to employ this target (named by Hypothesis 1-5). The hypotheses are as follows.

Hypothesis $1\left(H_{l}\right)$. Perceived Usefulness affects to Social Network Usage of students.

Hypothesis $2\left(\mathrm{H}_{2}\right)$. Perceived Ease of Use affects to Social Network Usage of students.

Hypothesis $3\left(H_{3}\right)$. Social Influences affects to Social Network Usage of students.

Hypothesis $4\left(H_{4}\right)$. Facilitating Conditions affects to Social Network Usage of students.

Hypothesis $5\left(H_{5}\right)$. Community Identity affects to Social Network Usage of students.

Besides, to answer the impact of social networks using on academic performance of students, hypothesis 6 confirms this target. The hypothesis is represented as follows.

Hypothesis $6\left(H_{6}\right)$. Social Network Usage affects to Academic Performance.

\subsection{Data Collection}

The questionnaire design for our study is referenced to some previous studies (Sanchez et al., 2014; Ainin et al., 2015). To answer our research questions as well as to confirm the above hypotheses, we conduct a stratified sampling survey including 600 undergraduate students studying in Ho Chi Minh City, Vietnam. After checking the validity, finally, the 576 correct samples (account for $96 \%$ of the survey sample) were encoded and analyzed by SPSS 20.0 software and AMOS software. In this research, the total number of study items is 35 and the survey sample has 576 observations, the data is responded to the conditions for testing the hypothesis (Hair et al., 2009). The participants answer questionnaires based on criteria such as the number of the academic years, major of students, gender, family register, age, and the number of years of using social networks. In detail, with the number of academic years of students, our survey will focus on the undergraduate students in the 2nd, 3rd, and 4th academic year in all academic majors. Our questionnaire form is designed based on the 5-point Likert scale to conduct measurement, where, it has a principle of from the lowest level 'strongly disagree' to the highest level 'strongly agree'. The data was collected by a direct survey done from January 2019 to March 2019.

The sample of demographic representatives in our study is presented through some factors such as gender, age, number of the academic years, number of years using social networks. The description of our data is fastly summarized in the below table (see Table 1).
Table 1. Descriptive analysis of the research sample

\begin{tabular}{|l|c|c|c|}
\hline \multirow{2}{*}{ Demographic } & Content & $\begin{array}{c}\text { Number of } \\
\text { respondents }\end{array}$ & Percent \\
\hline \multirow{2}{*}{ Gender } & Male & 206 & 35.7 \\
\cline { 2 - 4 } & Female & 370 & 64.3 \\
\hline \multirow{2}{*}{ Age } & $19-21$ & 502 & 87.1 \\
\cline { 2 - 4 } & $21-22$ & 74 & 12.9 \\
\hline \multirow{3}{*}{$\begin{array}{l}\text { Number of years } \\
\text { using social networks }\end{array}$} & Less than 3 years & 32 & 5.6 \\
\cline { 2 - 4 } & From 3 to 4 years & 147 & 25.5 \\
\cline { 2 - 4 } & 5 years or more & 397 & 68.9 \\
\hline \multirow{3}{*}{$\begin{array}{l}\text { Number of friends } \\
\text { on social networks }\end{array}$} & Less than 200 & 117 & 20.3 \\
\cline { 2 - 4 } & From 200 to 500 & 160 & 27.8 \\
\cline { 2 - 4 } & More than 500 & 299 & 51.9 \\
\hline \multirow{3}{*}{$\begin{array}{l}\text { Number of times } \\
\text { using social networks } \\
\text { per day }\end{array}$} & Less than 5 times & 185 & 32.1 \\
\cline { 2 - 4 } & $\begin{array}{c}\text { From 6 to 10 } \\
\text { times }\end{array}$ & 149 & 22.8 \\
\cline { 2 - 4 } & $\begin{array}{c}\text { More than 10 } \\
\text { times }\end{array}$ & 242 & 42.1 \\
\hline $\begin{array}{l}\text { Number of hours } \\
\text { using social network } \\
\text { per day }\end{array}$ & Less than 4 hours & 249 & 43.2 \\
\cline { 2 - 4 } & $\begin{array}{c}\text { More than 4 } \\
\text { hours }\end{array}$ & 327 & 56.8 \\
\hline
\end{tabular}

\section{Result and Discussion}

\subsection{Reliability Validity and Construct Validity}

In our estimated process, firstly, the scales of research concepts are assessed by computing the Cronbach's $\alpha$. Secondly, these scales continue to be tested through the Exploratory factor analysis (EFA) as well as the Confirmatory factor analysis (CFA). Finally, the Structural equation modeling (SEM) method is employed to test our theoretical model as well as the hypotheses.

Firstly, the scales of the components have passed the requirement of reliability (larger than 0.6) with the Cronbach's $\alpha$ values run from 0.701 to 0.919 (see Table 2) as well as the corrected item-total correlations of all scales are higher than 0.3 (see Kline, 1998).

Secondly, the variables will be tested by the exploratory factor analysis (EFA) progress. The EFA is known as a popular statistical method employed to uncover the identifying structure of a relatively large group of variables (Hair et al., 2009). EFA can be used to identify the underlying relationships between measured variables in a research model (Norris \& Lecavalier, 2009). A study item can be accepted if it has the factor loading is higher than 0.5 (Hair et al., 2009). There are 9 scales (from 35 scales of 7 variables) must be rejected from the research model because they have component values smaller than 0.5. With the final list of 26 scales, the KMO coefficient and Barlett's testing value is equal to 0.993 (larger than the threshold of 0.5 ) with a statistical significance at $1 \%$ level. Besides, the total extracted variance is $64.974 \%(>50 \%)$ 
concludes that the seven study factors can be explained by $64.974 \%$ of the data variability. Based on the testing indicators, there are 26 items of 7 variables (see Table 2) that can be gone in the next step of the study process (see Hair et al., 2009).

Thirdly, by employ the Confirmatory factor analysis (CFA), it well indicates which variables load on which factors as well as which factors are correlated, respectively. The most important objective of CFA is to test whether the collected data fit a hypothesized measurement model (Hair et al., 2009). Based on the CFA test, the received indicators can help to conclude about the fit of data to the research model. In detail, the CFA result shows that the Chi-square value is 745.81 (P-value is 0.000). Besides, the GFI, TLI, CFI indicators are: $0.955,0.930,0.944$ respectively larger than 0.9 ; RSMEA is equal to 0.054 (less than 0.08). Following the testing result, these parameters well meet the CFA requirements (see Kaplan 2008; Hair et al., 2009; Wu et al., 2017). So it is can conclude that the research model is consistent with the collected data.

Table 2. Reliability test for the variables

\begin{tabular}{|c|c|c|c|c|c|}
\hline Cons & struct/Items & Loading & Alpha & $\mathrm{CR}$ & AVE \\
\hline \multicolumn{6}{|c|}{ Perceived Usefulness (PU) } \\
\hline & PU01 & 0.793 & 0.802 & 0.777 & 0.537 \\
\hline & PU02 & 0.809 & & & \\
\hline & PU03 & 0.704 & & & \\
\hline \multicolumn{6}{|c|}{ Perceived Ease of Use (OU) } \\
\hline & OU01 & 0.779 & 0.904 & 0.903 & 0.728 \\
\hline & OU02 & 0.877 & & & \\
\hline & OU03 & 0.851 & & & \\
\hline & OU04 & 0.753 & & & \\
\hline \multicolumn{6}{|c|}{ Social Influence (SI) } \\
\hline & SI01 & 0.781 & 0.895 & 0.723 & 0.583 \\
\hline & $\mathrm{SI} 02$ & 0.664 & & & \\
\hline & SI03 & 0.695 & & & \\
\hline & SI04 & 0.661 & & & \\
\hline \multicolumn{6}{|c|}{ Facilitating Conditions (FC) } \\
\hline & FC01 & 0.740 & 0.854 & 0.753 & 0.612 \\
\hline & $\mathrm{FC} 02$ & 0.765 & & & \\
\hline & $\mathrm{FC} 03$ & 0.689 & & & \\
\hline \multicolumn{6}{|c|}{ Community Identity (CI) } \\
\hline & CI01 & 0.815 & 0.902 & 0.922 & 0.748 \\
\hline & CI02 & 0.868 & & & \\
\hline & $\mathrm{CI} 03$ & 0.846 & & & \\
\hline & $\mathrm{CI} 04$ & 0.808 & & & \\
\hline \multicolumn{6}{|c|}{ Social Network Usage (SN) } \\
\hline & SN01 & 0.792 & 0.701 & 0.785 & 0.549 \\
\hline & $\mathrm{SN} 02$ & 0.631 & & & \\
\hline & SN03 & 0.864 & & & \\
\hline & SN04 & 0.707 & & & \\
\hline \multicolumn{6}{|c|}{ Academic Performance (AP) } \\
\hline & AP01 & 0.894 & 0.919 & 0.915 & 0.739 \\
\hline & AP02 & 0.900 & & & \\
\hline & AP03 & 0.911 & & & \\
\hline & AP04 & 0.882 & & & \\
\hline Goodness-fit-indices: & $2 / \mathrm{df}=745.8$ & $4 ; \mathrm{GFI}=0.9$ & $0.930 ; \mathrm{R}$ & $A=0.054$ & \\
\hline
\end{tabular}




\subsection{Structural Equation Modeling Estimation}

The structural equation modeling (SEM) method is a well-known multivariate method used in quantitative analysis in social science. This method is popularly employed to test hypotheses regarding the influences among interacting variables in a quantitative research model (Kaplan, 2008). The SEM result shows that the estimated model has standardized values including the Chi-square is 934.323 with $\mathrm{df}=283$ ( $\mathrm{P}$-value is 0.000 ), Chi-square/df is $3.3(>2)$. Other indicators are higher than
0.9 including GFI $=0.965$, TLI $=0.904$, CFI $=0.923$ (higher than 0.9). Besides, RMSEA value is 0.063 (smaller than 0.08). Based on these criteria, the research model has been achieved compatibility with the collected data (see Hair et al., 2009; Wu et al., 2017). In this section, the SEM method is used to estimate the impact of social network usage on the academic performance of students in Vietnam. The estimated result in the below table represents the coefficients which imply the effects among the variables (see Table 3).

Table 3. Results of the structural model

\begin{tabular}{|c|c|c|c|c|c|c|c|}
\hline Dependent variable & & Independent variable & $\begin{array}{l}\text { Standardized } \\
\text { Estimate }\end{array}$ & SE & $t$-value & $p$-value & Conclusion \\
\hline Social Network Usage & $<---$ & Perceived Usefulness & 0.419 & 0.075 & 5.598 & $* * *$ & Accepted $\mathrm{H}_{1}$ \\
\hline Social Network Usage & $<---$ & Perceived Ease of Use & 0.125 & 0.062 & 2.024 & $* * *$ & Accepted $\mathrm{H}_{2}$ \\
\hline Social Network Usage & $<---$ & Social Influence & 0.256 & 0.074 & 3.459 & $* * *$ & Accepted $\mathrm{H}_{3}$ \\
\hline Social Network Usage & $<---$ & Facilitating Conditions & 0.082 & 0.099 & .834 & 0.405 & Rejected $\mathrm{H}_{4}$ \\
\hline Social Network Usage & $<---$ & Community Identity & 0.244 & 0.054 & 4.560 & $* * *$ & Accepted $\mathrm{H}_{5}$ \\
\hline Academic Performance & $<---$ & Social Network Usage & 0.532 & 0.045 & 11.846 & $* * *$ & Accepted $\mathrm{H}_{6}$ \\
\hline \multirow[t]{3}{*}{ Goodness-of-fit indices } & \multirow{3}{*}{\multicolumn{2}{|c|}{$\square^{2} / \mathrm{df}=934.323 / 283=3.301 ; p<0.001$}} & \multicolumn{2}{|c|}{$\mathrm{CFI}=0.923$} & & \multicolumn{2}{|c|}{$\mathrm{TLI}=0.904$} \\
\hline & & & \multicolumn{2}{|c|}{$\mathrm{GFI}=0.965$} & & \multicolumn{2}{|c|}{ AGFI $=0.822$} \\
\hline & & & \multicolumn{2}{|c|}{ RMSEA $=0.063$} & & & \\
\hline
\end{tabular}

Note: $\quad * * * p<0.01, * * p<0.05, * p<0.1 . \mathrm{SE}=$ Standard Error

Furthermore, the SEM result presents that all regression coefficients are positive, however, there are only 5 regression coefficients are statistically significant. In detail, there are four independent variables that positively impact the mediating variable (Social network usage - SN) with the statistical significance at $1 \%$, including the Perceived usefulness (PU) with $\beta=0.419$, Perceived ease of use (EU) with $\beta=0.125$, Social influence (SI) has $\beta=0.256$, and Community identity (CI) has $\beta=0.244$. The Facilitating conditions (FC) has a positive effect $(\beta=0.082)$ on the Social network usage $(\mathrm{SN})$, however, its coefficient is not statistically significant. Finally, the Social network usage (SN) variable has a positive effect $(\beta=0.532)$ on the Academic performance (AP) at $1 \%$. Following the estimated result, there are five hypothesizes $\left(\mathrm{H}_{1}, \mathrm{H}_{2}\right.$, $\mathrm{H}_{3}, \mathrm{H}_{5}, \mathrm{H}_{6}$ ) that are confirmed with an accepted conclusion. The figure of the SEM result is described below (see Figure 2).

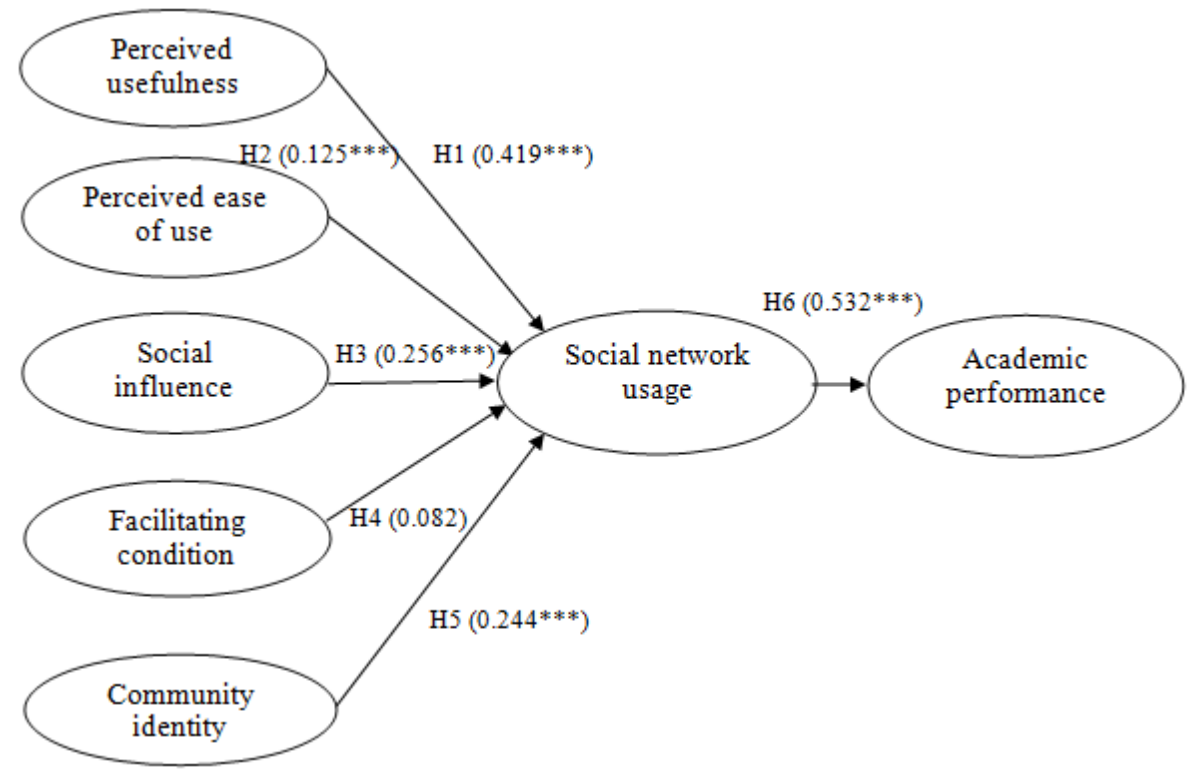

Figure 2. Result of the structure estimation 
Following the evidence, our research results confirm the positive impact of social media usage on the academic performance of students in the case of Vietnam. In the context of the modern learning environment with e-learning applications based on the Internet, social networks help students in many ways, such as reading, learning, find information, interact, or cooperate with others. Social networking is an effective and fast interactive environment helping to learn processes more effectively. Our research result is unified with some previous studies done by authors such as Ainin et al. (2015), Amin et al. (2016), Michikyan et al. (2015), or Khalid (2017). However, the educational managers in Vietnam need to guide students to use social networks for study purposes to spread the positive effects of these tools. On the contrary, if the Vietnamese students use social networks more for the purpose of expressing themselves in the coming time, their academic results will be decreased as recommended by some authors, such as Michikyan et al. (2015).

\section{Conclusions and Implication}

This study aims to explore the effect of social network usage on the academic performance of students in the case of Vietnam. A sample including 576 respondents is collected to answer the research questions. Our finding is that social network usage has a positive impact on the academic performance of students at a significant at $1 \%$. Besides, social network usage is a popular habit when almost the students use it for five years or more and the usage time is quite long. Furthermore, social networks are a popular connection tool within the community for students, in which, all accounts have a rather large number of friends with $52 \%$ of students having about 500 friends or more as well as social networks taking them from 15 to 45 minutes per time of using.

Learning activities are also conducted but not must be the main activity with $53 \%$ using social networks to group learning and monitor group activities. Social networks are also a channel to help students monitor school and class activities. Besides, social networks are not only a tool used by students for the purpose of communication, entertainment, etc.. but also a tool to support effective learning. Through the research results presented above, we find that using social networks in a logical way will help students achieve better academic performance results. Using social networks for the purpose of learning and expressing oneself is directly related to the academic results of students.

Based on the study results, there are some implications for the managers as follows. Firstly, it needs to continue to promote communication activities, promote the image of the school to students through social networks. Secondly, organize volunteer groups (maybe from students) in continuously using social networks to post news and articles to serve the school's communication to students. Thirdly, activities of the team need to exploit thoroughly promote social activities in implementing these activities. Fourthly, class monitors need to set up classroom social accounts to better connect members' activities. Learning activities should be combined with social networks such as case studies, study surveys to use it more effectively for social learning purposes. Fifthly, continue to maintain activities for learning purposes: look up dictionaries, search online documents, download documents, etc... to update many ideas new knowledge in addition to the knowledge received on the lecture. Finally, learning results and track information on the school website such as timetable, training activities, should be updated as fast as possible.

\section{Limitation and Suggestions for Further Study}

There are some limitations that can be seen in this study. Firstly, the research sample is quite small and only collected in Ho Chi Minh City. It is better if there are more students from other Vietnamese cities having participated in the survey data. Secondly, there are some other factors that may affect the academic performance of students not included in our research models, such as the Socialization, or Social Acceptance. Therefore, future studies can consider these variables.

\section{REFERENCES}

[1] Abed, S. S. (2020). Social commerce adoption using TOE framework: An empirical investigation of Saudi Arabian SMEs. International Journal of Information Management, 53, 102118.

[2] Ainin, S., Naqshbandi, M. M., Moghavvemi, S., \& Jaafar, N. I. (2015). Facebook usage, socialization and academic performance. Computers \& Education, 83, 64-73.

[3] Amin, Z., Mansoor, A., Hussain, S. R., \& Hashmat, F. (2016). Impact of Social network of Student's Academic Performance. International Journal of Business and Management Invention, 5(4), 22-29.

[4] Al-Rahmi, W. M. , Zeki, A. M., Alias, N., Saged, A. (2017). Use of social media and its impact on academic performance among university students in Malaysian Higher Education. Anthropologist, 28(1-2), 52-68.

[5] Bond, R. M., Chykina, V., \& Jones, J. J. (2017). Social network effects on academic achievement, The Social Science Journal, 54(4), 438-449.

[6] Corrocher, N. (2011). The adoption of Web 2.0 services: an empirical investigation. Technological Forecasting \& Social Change, 78(4), 547-558. 
[7] Cheung, C. M. K., Chiu, P. Y., \& Lee, M. K. O. (2011) Online social networks: why do students use Facebook? Computers in Human Behavior, 27(4), 1337-1343.

[8] Dholakia, U. M., Bagozzi, R. P., \& Pearo, L. K. (2004). A social influence model of consumer participation in network and small group based virtual communities. International Journal of Research in Marketing, 21, 241-263

[9] Davis, F. D. (1989). Perceived usefulness, perceived ease of use, and user acceptance of information technology. MIS Quarterly, 13(3), 319-340.

[10] Kalpidou, M., Costin, D., \& Morris, J. (2011). The relationship between Facebook and the well-being of undergraduate college students. CyberPsychology, Behavior, and Social Networking, 14(4), 183-189.

[11] Kaplan, A. M., \& Haenlein, M. (2010). Users of the world, unite! The challenges and opportunities of social media. Business Horizons, 53, 59-68.

[12] Kaplan, D. (2008). Structural Equation Modeling: Foundations and Extensions (2 $2^{\text {nd }}$ Edition). SAGE. ISBN 978-1412916240.

[13] Karadkar, A. (2015). The impact of social media on student life. Technician, http://www.technicianonline.com/opinion/ article d1142b70-5a92-11e5-86b4-cb7c98a6e45f.html. Accessed 26 May 2019.

[14] Kirschner, P. A., \& Karpinski, A. C. (2010). Facebook and academic performance. Computers in Human Behavior, 26(6), 1237-1245

[15] Kim, C., Lee, S.-G., \& Kang, M. (2012). I became an attractive person in the virtual world: users' identification with virtual communities and avatars. Computers in Human Behavior, 28(5), 1663-1669.

[16] Khalid, H. (2017). The effect of Social networks on Pakistani students. Journal of Information Technology \& Software Engineering, 7(3), 1000203.

[17] Kline, R. B. (1998). Principles and practice of structural equation modeling. Guilford Publications, New York, USA.

[18] Köse U. (2016). Effects of Social Media on Students: An Evaluation Approach in Turkey. In: Issa T., Isaias P., Kommers P. (eds) Social Networking and Education. Lecture Notes in Social Networks. Springer, Cham.

[19] Hair, Jr. J. F., Black, W. C., Babin, B. J., \& Anderson, R. E. (2009). Multivariate Data Analysis ( $7^{\text {th }}$ Editions), Upper Saddle River, NJ: Prentice Hall, USA.

[20] Mazman, S. G., \& Usluel, Y. K. (2009). Adoption of Web 2.0 tools in distance education. Procedia Social and Behavioral Sciences, 1(1), 818-823.

[21] Martin, J., Gonçalves, R., Oliveira, T., Cotac, M., Branco, F. (2016). Understanding the determinants of social network sites adoption at firm level: A mixed methodology approach. Electronic Commerce Research and Applications, 18, 10-26.

[22] Michikyan, M., Subrahmanyam, K., \& Dennis, J. (2015). Facebook use and academic performance among college students: A mixed-methods study with a multi-ethnic sample. Computers in Human Behavior, 45, 265-272.

[23] Nadkarni, A., \& Hofmann, S. G. (2012). Why do people use Facebook?. Personality and Individual Differences, 52(3), 243-249.

[24] Norris, M., \& Lecavalier, L. (2009). Evaluating the Use of Exploratory Factor Analysis in Developmental Disability Psychological Research. Journal of Autism and Developmental Disorders, 40(1), 8-20. doi:10.1007/s10803 -009- 0816-2. PMID 19609833.

[25] Rains, S. A., \& Young, V. (2009). A meta-analysis of research on formal computer-mediated support groups: examining group characteristics and health outcomes. Human Communication Research, 35(3), 309-336.

[26] Rouis, S., Limayem, M., \& Salehi-Sangari, E. (2011). Impact of Facebook usage on students' academic achievement: Role of self-regulation and trust. Electronic Journal of Research in Educational Psychology, 9(3), 961-994.

[27] Sánchez, R. A., Cortijo, V., \& Javed, U. (2014). Students' perceptions of Facebook for academic purposes. Computers \& Education, 70, 138-149.

[28] Shahzad, B., Alwagait, E., \& Alim, S., (2015). Investigating the Relationship between Social Media Usage and Students' Grades in Saudi Arabia: A Mixed Method Approach, The Proceeding of the Conference Recent Advances in Electrical Engineering and Educational Technologies.

[29] Shepherd, H., \& Lane, J. (2019). In the mix: Social intergration and social media adoption. Social Science Research, 82, 1-17.

[30] Tandoc Jr, E. C., Ferrucci, P., \& Duffy, M. (2015). Facebook use, envy, and depression among college students: Is facebooking depressing?. Computers in Human Behavior, $43,139-146$

[31] Torres, L., Royo, S., \& Garcia-Rayado, J. (2020). Social media adoption by Audit Institutions. A comparative analysis of Europe and the United States. Government Information Quarterly, 37(1), 101433.

[32] Venkatesh, V., Morris, M. G., Davis, G. B., \& Davis, F. D. (2003). User acceptance of information technology: toward a unified view. MIS Quarterly, 27(3), 425-478.

[33] Wu, Z., Yu, A. T. W., \& Shen, L. (2017). Investigating the determinants of contractor's construction and demolition waste management behavior in Mainland China. Waste Management, 60, 290-300. 